\title{
The continuum of screening and early detection, awareness and faster diagnosis of lung cancer
}

\author{
Michael D Peake, ${ }^{1,2,3,4}$ Neal Navani, ${ }^{5,6}$ David R Baldwin ${ }^{7}$
}

The principal reason lung cancer outcomes are poor is that most patients are diagnosed with what, with current technologies, is incurable disease. Despite unprecedented recent advances in the understanding of the biology, oncogenesis and immunology of cancer, and the subsequent development of innovative systemic therapies for lung cancer, the long-term prognosis for patients beyond stages I and II remains poor. The cost of the new agents, largely indicated for people with advanced disease and good performance status (PS), is such that the International Agency for Research on Cancer recently said that 'No country can afford to treat its way out of the cancer problem'. ${ }^{1}$ In any case, many patients with advanced disease are ineligible because of poor performance status.

Although lung cancer survival rates have been improving in England since $2006,{ }^{2}$ the latest data from the Concord study still rate the UK behind many other nations. ${ }^{3}$ Later diagnosis is likely a major factor explaining the consistent observation that the proportion of patients that have early stage disease at the time of diagnosis in the UK is less than in many comparator countries. ${ }^{4}$ In a recent study comparing older patients with non-small cell lung cancer (NSCLC) in England with those in the USA, 15\% were diagnosed at stage I in England compared with $25 \%$ in the USA. ${ }^{5}$

To address these issues, we need to consider ways in which we can detect lung cancer at an earlier stage to increase the

\footnotetext{
${ }^{1}$ Department of Respiratory Medicine, University of Leicester, Leicester, UK

${ }^{2}$ Centre for Cancer Outcomes, Cancer Collaborative, University College London Hospitals, London, UK ${ }^{3}$ National Cancer Registration and Analysis Service, Public Health England, London, UK

${ }^{4}$ Department of Thoracic Medicine, University College London Hospitals, London, UK

${ }^{5}$ Lungs for Living Research Centre, UCL Respiratory, University College London, London, UK

${ }^{6}$ Department of Early Diagnosis and Health Professional Engagement, Cancer Research UK, London, UK ${ }^{7}$ Department of Respiratory Medicine, University of Nottingham, Nottingham, UK
}

Correspondence to Dr Michael D Peake, Respiratory Medicine, University of Leicester, Leicester LE1 7HA, UK; mick.peake@phe.gov.uk curative treatment rate, and where cancer is detected at a later stage, provide rapid work-up to minimise deterioration in fitness to maximise the impact of systemic therapy. Essentially this means: screening of people at relatively high risk of lung cancer; using public and professional awareness campaigns to promote the earlier referral of patients with symptoms suspicious of a diagnosis of lung cancer; and rapid and accurate diagnosis of those being referred to secondary care.

The evidence base for lung cancer screening with low-dose CT has been building, recently having been collated in a European position statement, ${ }^{6}$ and many countries are now implementing screening programmes in one form or another. The position of the UK National Screening Committee ${ }^{7}$ is currently that 'Systematic population screening programme (is) not recommended' and is awaiting the European NELSON trial ${ }^{8}$ to report. In the meantime, as evidenced by a CRUK-sponsored event in April 2018, ${ }^{9}$ clinical pressure within the UK is growing and a number of pilot programmes have emerged, implementing 'high-risk case finding' initiatives using some form of 'Lung Health Check' approach. Such programmes in Manchester and Liverpool have already reported 2\%-3\% detection rates with both high rates of stage I lung cancer and high curative treatment rates. ${ }^{1011}$ Such an approach has now been endorsed by NHS England and further pilots are planned.

Most patients with early stage lung cancer are either asymptomatic or have vague and non-specific symptoms, which make early recognition by both patients and primary care clinicians difficult. However, there is evidence that there are potential missed opportunities in primary care in the 3-6 months before diagnosis. ${ }^{12}$ As a result, a number of programmes have been developed to increase awareness of the symptoms and the potential benefits of early diagnosis of lung cancer. The first of these was in the Doncaster area ${ }^{13}$ where persistent cough was chosen as the alert symptom. This innovative study was limited by relatively small numbers, but prompted a number of regional campaigns under the banner of the National Awareness and Early Diagnosis Initiative (NAEDI). ${ }^{14}$ The most successful of these is reported in Thorax ${ }^{15}$ where a combined approach to public and primary care awareness of persistent cough as a warning symptom, combined with 'walk-in' chest $\mathrm{X}$-ray facilities in more deprived areas of Leeds is described. Community-ordered chest X-rays almost doubled and a significant stage shift towards earlier stage lung cancer was shown, with an 8.8 percentage point increase in the proportion of patients diagnosed with stage I/II lung cancer (26.5\% pre-campaign vs $35.3 \%$ during campaign) and a $9.3 \%$ reduction in the absolute number of patients diagnosed with stage III/IV disease. Over the period of the intervention, the proportion of patients undergoing treatment with curative intent increased from $16.8 \%$ to $30.6 \%$, the 1 -year survival rate rose from $30.3 \%$ to $39.1 \%$ and the proportion of patients diagnosed as part of an emergency presentation fell from $37.1 \%$ to $29.1 \%$. The authors are rightly cautious because the temporal comparison means that a causal link between the campaign and stage-shift cannot be proven and other factors (particularly the emergence of SABR as a therapeutic option over the period of the study), could explain some of the findings. However, it seems unlikely, given that all of the findings are consistent with earlier diagnosis, that the intervention was not the main cause of improvement in outcomes that now approach those in other comparable countries. ${ }^{5}$

Over a similar period, the national programmes of promoting public awareness in cancer, the 'Be Clear On Cancer' campaigns, were introduced, beginning with a regional and then three national campaigns advertising 'cough for 3 weeks or more' as an alert symptom for lung cancer. ${ }^{16}$ The evaluation of these campaigns showed a doubling of 2ww referrals between 2011 and 2015, with the rate of rise faster after the first campaigns and a statistically significant shift towards earlier stage disease after all the national campaigns. ${ }^{16}{ }^{17}$ As with the authors of the Leeds study referred to above, it was accepted that proving a causal relationship was not possible, but it was concluded that there was evidence of a 'whole system response', starting with increased public recognition of the messages to increases in attendance at general practitioner (GP) practices, then increases in urgent suspected cancer referrals from GPs to secondary care. There was evidence of an increased number of cases, more use of diagnostic tests, a shift to earlier stage disease, better PS at the time of 
diagnosis and increased numbers of patients undergoing surgery. There was no evidence of a statistically significant improvement in 1-year survival directly related to the campaigns.

'Rapid Diagnosis' is a relatively new term but has long been supported by the cancer waiting times targets in the UK and more recently by the more challenging targets set by the Independent Cancer Taskforce. ${ }^{18}$ The UK Government is now promoting the implementation of a 'National Optimal Lung Cancer Pathway', ${ }^{19}$ one aim of which is to reduce the interval from referral to decision to treat to a maximum of 28 days. While the relationship between this interval and survival in cancer is complex, ${ }^{20}$ there is little doubt that a matter of weeks' delay in treatment can be significantly detrimental to survival. Even within the six sub-stages from stage $1 \mathrm{a}$ to $2 \mathrm{~b}$ in the new 8 th UICC classification of tumour stage in NSCLC, the prognosis for 5 -year survival varies from $92 \%$ to $46 \%$. $^{21}$ We know that the doubling time of some NSCLC tumours can be as short as 1-2 months ${ }^{22}$ and in one recent study, 5 -year survival was found to be significantly worse in patients where surgery was delayed beyond 38 days and progressively worsened as time to surgery increased. ${ }^{23}$ O'Rourke and colleagues demonstrated that, while waiting for radical radiotherapy in Scotland, $21 \%$ of their patients progressed to the point where only palliative treatment was feasible. ${ }^{24}$ Apart from a stage shift over a typical period of waiting for diagnosis and treatment, patients of borderline fitness can deteriorate from being fit for treatment with curative intent at the time of referral to being fit only for palliative treatments by the time treatment can be started. The only randomised trial of the impact of a rapid diagnostic pathway compared with 'standard' care is the Lung-BOOST trial ${ }^{25}$ in which the median interval between referral and diagnosis was reduced by 15 days and the median survival increased by 191 days. Also, for those patients who have advanced disease, PS can deteriorate rapidly, making systemic treatment less effective or impossible. Delays in diagnosis and treatment also distress patients and carers, providing another important reason to achieve rapid diagnosis.

Screening, early diagnosis and rapid diagnosis represent interventions in a continuum of the progress of people with lung cancer. In all of these, earlier is better, but one intervention alone is not enough as only a minority of patients will benefit. Integrating these initiatives by identifying people and populations at risk may be a key to their more effective use. Public and professional awareness programmes highlighting both the risk profile of patients and the value of early diagnosis need to continue and to be constantly evaluated and improved; screening or 'highrisk case-finding programmes should be implemented now, and every healthcare provider should be working towards the universal implementation of a rapid diagnostic pathway. The work of the Leeds group $^{15}$ demonstrates one way of making significant inroads into reducing the impact of this commonly fatal disease but clearly more needs to do be done.

Contributors MP was commissioned to write this editorial and wrote the first draft. DB and NN made significant comments and amendments and the final version was agreed by all authors.

Funding The authors have not declared a specific grant for this research from any funding agency in the public, commercial or not-for-profit sectors.

\section{Competing interests None declared.}

Provenance and peer review Commissioned; internally peer reviewed.

(C) Author(s) (or their employer(s)) 2018. No commercial re-use. See rights and permissions. Published by BMJ.

\section{Check for updates}

To cite Peake MD, Navani N, Baldwin DR. Thorax 2018;73:1097-1098.

Accepted 30 July 2018

Published Online First 10 August 2018

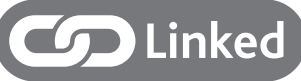

- http://dx.doi.org/10.1136/thoraxjnl-2018-211842

Thorax 2018;73:1097-1098.

doi:10.1136/thoraxjnl-2018-212189

\section{REFERENCES}

1 Wild C. International Agency for Research on Cancer. https://www.iarc.fr/en/cancerprevention/interviews_ talks.php

2 Walters S, Benitez-Majano S, Muller P, et al. Is England closing the international gap in cancer survival? $\mathrm{Br} J$ Cancer 2015;113:848-60.

3 Allemani C, Matsuda T, Di Carlo V, et al. Global surveillance of trends in cancer survival 2000-14 (CONCORD-3): analysis of individual records for 37513025 patients diagnosed with one of 18 cancers from 322 population-based registries in 71 countries. Lancet 2018:391:1023-75.

4 Walters S, Maringe C, Coleman MP, et al. and the ICBP Module 1 Working Group. Lung cancer survival and stage at diagnosis in Australia, Canada, Denmark, Norway, Sweden and the United Kingdom: a population-based study, 2004-2007. Thorax 2013;68:551-64.

5 Andreano A, Peake MD, Janes SM, et al. The Care and Outcomes of Older Persons with Lung Cancer in England and the United States, 2008-2012. J Thorac Oncol 2018;13:904-14.

6 Oudkerk M, Devaraj A, Vliegenthart R, et al. European position statement on lung cancer screening. Lancet Oncol 2017:18:e754-66.
7 UK National Screening Committee. Current UK NSC recommendations. https://legacyscreening.phe.org.uk/ screening-recommendations.php

8 Yousaf-Khan U, van der Aalst C, de Jong PA, et al. Final screening round of the NELSON lung cancer screening trial: the effect of a 2.5-year screening interval. Thorax 2017;72:48-56

9 CRUK closed international workshop report (Submitted to Lung Cancer 2018).

10 Crosbie PA, Balata H, Evison M, et al. Implementing lung cancer screening: baseline results from a community-based 'Lung Health Check' pilot in deprived areas of Manchester. Thorax. doi: 10.1136/ thoraxjnl-2017-211377. [Epub ahead of print 13 Feb 2018].

11 Field JK, Marcus M, Maroni R, et al. Liverpool Healthy Lung project: Preliminary report for the first three neighbourhoods: Everton, Picton and Speke. 2017. https://www.liverpoolccg.nhs.uk/media/ 2665/liverpool-healthy-lung-project-report_final.pdf (accessed 06 Jul 2018).

12 lyen-Omofoman B, Tata LJ, Baldwin DR, et al. Using socio-demographic and early clinical features in general practice to identify people with lung cancer earlier. Thorax 2013:68:451-9.

13 Athey VL, Suckling RJ, Tod AM, et al. Early diagnosis of lung cancer: evaluation of a community-based social marketing intervention. Thorax 2012;67:412-7.

14 Richards MA. The National Awareness and Early Diagnosis Initiative in England: assembling the evidence. Br J Cancer 2009;101(Suppl 2):S1-4.

15 Kennedy MPT, Cheyne L, Darby M, et al. Lung cancer stage-shift following a symptom awareness campaign. Thorax 2018;73:1128-36.

16 Peake MD. National Cancer Registration and Analysis Service, Public Health England. Be Clear on Cancer: Regional and national lung cancer awareness campaigns 2011 to 2014: Final evaluation results. http://www.ncin.org.uk/view?rid=3633

17 Ironmonger L, Ohuma E, Ormiston-Smith N, et al. The impact of public awareness campaigns for lung cancer. Br J Cancer 2015;112:207-16.

18 Independent Taskforce. Achieving World-Class Cancer Outcomes: A Strategy for England 2015-2020. https://www.cancerresearchuk.org/sites/default/ files/achieving_world-class_cancer_outcomes_-_a strategy_for_england_2015-2020.pdf (accessed 09 Jul 2018).

19 Commissioning Guidance / National Optimal Lung Cancer Pathway. 2018. https://www.roycastle.org/ how-we-help/lung-cancer-information/information-forhealthcare-professionals/commissioning-guidance

20 Hamilton W, Walter FM, Rubin G, et al. Improving early diagnosis of symptomatic cancer. Nat Rev Clin Oncol 2016;13:740-9.

21 Rami-Porta R, Bolejack V, Crowley J, et al. The IASLC lung cancer staging project: proposals for the revisions of the T Descriptors in the forthcoming eighth edition of the TNM Classification for Lung Cancer. J Thorac Oncol 2015;10:990-1003

22 Callister MEJ, Baldwin DR, Akram AR, et al. British Thoracic Society guidelines for the investigation and management of pulmonary nodules: accredited by NICE. Thorax 2015;70:ii1-54.

23 Yang C-FJ, Wang H, Kumar A, et al. Impact of timing of lobectomy on survival for clinical stage IA lung squamous cell carcinoma. Chest 2017;152:1239-50.

24 O'Rourke N, Edwards R. Lung cancer treatment waiting times and tumour growth. Clin Oncol 2000; 12:141-4.

25 Navani N, Nankivell M, Lawrence DR, et al. Lung cancer diagnosis and staging with endobronchial ultrasound-guided transbronchial needle aspiration compared with conventional approaches: an openlabel, pragmatic, randomised controlled trial. Lancet Respir Med 2015;3:282-9. 